\title{
THE DONALDSON REPORT, PARTNERSHIP AND TEACHER EDUCATION
}

\section{ANNA BECK AND PAUL ADAMS}

[Chapter Author 1: Dr Anna Beck, University of Strathclyde]

[Chapter Author 1 anna.beck@strath.ac.uk]

* [Chapter Author 2 Dr Paul Adams, University of Strathclyde]

[Chapter Author 2 paul.adams@strath.ac.uk]

Author/s Biography/ies:

Dr Anna Beck is a lecturer in Teacher Professional Learning at the University of Strathclyde. Her research interests span education policy, education reform and professional learning. She draws on network ethnographic methods in order to uncover policy processes, with a particular focus on the representation of teacher voice. Her current research explores the rise of evidence-based practice in Scotland, England and Germany and the politicisation of teacher research. She is a Co-Investigator on the Scottish Government funded MQuITE project.

Dr Paul Adams' work is primarily concerned with theoretical expositions on education policy. He has published widely in the areas of English and Scottish education policy, in particular when applied to pedagogy and on heuristic proposals for an understanding of policy processes and research. His work uses theoretical positions such as Positioning Theory, and philosophy to examine the ways in which policy might be better understood as an essentially intersubjective experience. He is currently CoPrincipal Investigator on the Scottish Government funded MQuITE project.

This is a peer-reviewed, accepted author manuscript of the following chapter: Beck, A. and Adams, P. (2020), "The Donaldson Report, Partnership and Teacher Education", Shanks, R. (Ed.) Teacher Preparation in Scotland (Emerald Studies in Teacher Preparation in National and Global Contexts), Emerald Publishing Limited, Bingley, pp. 63-78. https://doi.org/10.1108/978-1-83909-480-420201006 


\section{ABSTRACT:}

At the centre of recent reforms relating to Scottish teacher education is the report of a large-scale review, 'Teaching Scotland's Future' (Donaldson, 2011). This chapter provides a critical overview of one aspect of the review, namely partnership. Two key agendas underpinned the 50 recommendations contained in the Donaldson Report: the development and strengthening of partnership between universities, local authorities and schools; and, the modernisation and 'reinvigoration' of teacher professionalism. In 'Teaching Scotland's Future' it was argued that both of these are required for the development of 'high quality' teachers through initial teacher education. The report positioned teaching as an intellectual occupation, highlighting the complexity involved, making clear that teacher preparation should remain within the context of higher education.

Although the key messages from 'Teaching Scotland's Future' received support from across the education sector, the extent to which they have been achieved in practice remains unclear. We will explore the extent to which this key text has been translated into current initial teacher education provision through results from the Measuring Quality in Initial Teacher Education (MQuITE) Project and the ways in which partnership was experienced in post-Donaldson working. Through this partnership working will be examined in Scotland. The chapter will conclude by considering where we are now, and some final thoughts will be presented about the role that 'Teaching Scotland's Future' can play in a changing partnership policy landscape.

\section{KEYWORDS:}

1. Scottish education

2. Partnership

3. The Donaldson Review

4. Donaldson Report 


\section{Introduction}

Over the last twenty years, Scottish teacher education has been subject to reform, part of which was a large-scale review of teacher education, resulting in the publication of 'Teaching Scotland's Future', also known as the Donaldson Report (Donaldson, 2011). The report contained fifty recommendations to improve career-long teacher education, a main plank of which was a reconsideration of partnership working between universities, schools and local authorities. Although key messages from the report received widespread support, almost ten years on, the extent to which these recommendations have been achieved remains unclear. This chapter presents a critical examination of which elements have affected Initial Teacher Education with respect to partnership.

The chapter begins by noting the importance of partnership in teacher preparation. Following this, wider Scottish policy is considered for the way in which it has impacted on the development of partnership working. The chapter then draws, briefly, on findings from two separate research projects (Beck, 2016; Measuring Quality in Initial Teacher Education). The first explores the partnership processes that culminated in the Donaldson Report itself. In the second, data from the Measuring Quality in Initial Teacher Education (MQuITE) Project highlights the ways in which Higher Education Institution staff view partnership (Rauschenberger, Adams, \& Kennedy, 2017). The chapter concludes by identifying how partnership in relation to teacher preparation might develop in future.

\section{The importance of partnership}

School-university partnerships are a central feature of teacher preparation across the globe and are often promoted as the one defining feature of reform (Allen, Ambrosetti, \& Turner, 2013). However, it is often noted that partnerships do not always work due to, for example, time and differences in culture and tradition between different actors (Allen, Ambrosetti, et al., 2013). There abound, however, a plethora of models for partnership: For some (e.g. Maandag, Deinum, Hofman, \& Buitink, 2007) the model centres on the relationship between university supervisor, student and school, and ranges from workplace models (students engaged in fixed term placements), through to training schools (where students are located for most if not all of their time in one school). Often, mechanisms exist to support the development of partnerships, for example through co-ordinators, partners or networks (LilleJord \& Børte, 2016). This said, power imbalances between actors often mitigate against effective working and can privilege one group over another (LilleJord \& Børte, 2016). To counter, Akkerman \& Bruining (2016) discuss how various partnership models can work through 'boundaries'; here partnership requires organisational change including new relationships and cultures. Boundaries are described as '...sociocultural differences between practices leading to discontinuities in action or interaction' (page 243). Rooted in a desire to develop research as the defining parameter for ITE, Akkerman \& Bruining (2016) signal the need for partnership to be part of everyday practices within schools and HEls, rather than a bolt-on.

Partnership, then, may be difficult to achieve: cross-institutional collaboration requires high quality, strategic leadership (LilleJord \& Børte, 2016). Problematically, the university, with its concentration on research and theory, can be set against the practical features of schools. This theory-practice gap is widely discussed in the literature and the separation of roles is often proposed as a reason for partnership failure. Indeed, separating theory from practice is problematic given that the two are important for the creation of teacher-professionals (Allen, Howells, \& Radford, 2013). One way this might be countered is through the defining and use of third space (LilleJord \& Børte, 2016) where, 
...the school's practice culture meets the teacher education institution's academic culture. In this joint space for deliberation, tacit knowledge is made explicit, as participants have to explain activities which normally, in their own knowledge culture, they might take for granted. Through these encounters, the participants become aware of the historical and cultural context of their activities, and when norms are challenged, innovative thinking evolves. (LilleJord \& Børte, 2016: 558).

Such orientations mirror discussions which draw on dialectical approaches to theory and practice, so encouraging student reflection. They doubly legitimise different forms of knowing between universities and schools (Smith, Brisard, \& Menter, 2006). It is the case that such 'collaborative' models of partnership grew out of dissatisfaction with HEl-led (imparting knowledge) and complementary (theory-practice bridging) methodologies (Cohen, Hoz, \& Kaplan, 2013). The top-down nature of the former drew on HEl knowledge as the precursor to the development of new teachers with support from a small cadre of school-based staff whilst the latter centred on the need for the student to bring together the separate worlds of university and school (Furlong, Campbell, Howson, Lewis, \& McNamara, 2006). Collaborative models centre on joint planning and delivery in juxtaposition to other atomised methods. They encourage concern with epistemological and pedagogical implications of what and how students learn (Furlong et al., 2006). As Bartholomew \& Sandholtz (2009: 156) note, the underlying success of such partnerships is that they '...offer a means of ending the fragmented approach to teacher education, professional development, and school improvement.' Collaboration has the potential to bridge theory-practice divides, and also strengthen HEl-school relationships (Allen, 2011). If partnership can be construed as the sum total of all experiences teachers (student and otherwise) enter into on their journey towards professional recognition, it can be argued that, partnership is '...a strategy to structure, organise, strengthen and professionalise teacher education, while simultaneously renewing teaching practices in both institutions' (LilleJord \& Børte, 2016: 555).

There are two points to note here. First, partnership is not only concerned with what happens on placement (periods when students are working in school); rather, it should, under collaborative approaches, involve all aspects of teacher education. Second, there is no doubt that governments often position teacher education through, for example, a desire for quantifiable measures, which may drive a concentration on maximum pupil uplift on educational tests, or the removal of opportunities for student teachers to work in 'high-value' examination classes. The research-driven, exploratory nature of collaborative professional development may sit at odds with the outcomes-driven immediacy of contemporary classrooms. Consequently, the development of relationships in such environments may well be more akin to surveillance and mistrust than professional autonomy and creativity.

[P]erformance-based measures of teacher efficacy may explain teachers' predilection toward product- and standards-driven learning, which in turn can work against other mechanisms for teacher development such as professional learning communities. (Bartholomew \& Sandholtz, 2009: 157)

With this in mind, there is a need to consider the ways in which wider Scottish (education) policy orients the work of actors as well as moves to extol and embed partnership, for such positions mark particular features for the development of social and public policy in matters such as teacher education.

\section{Scottish (educational) policy positions}


Scotland's education system has always developed separately from the education systems in the rest of the UK and is often drawn on by political actors to express a sense of distinctiveness and superiority (Anderson, 2018). Even though it might be argued that Scottish education developments have mirrored changes in other countries, such as Sweden, certainly different attitudes towards individualism and collectivism have held sway (Paterson, 2003a). Further, since the establishment of the Scottish Executive, now termed the Scottish Government, in 1999, policy differences have become even more evident between Scotland and rest of the UK that reflect a more collective ideology for the former (Scott and Wright, 2012). The drive to address poverty became markedly 'Scottish' following devolution (Scott and Wright, 2012) and policy identified structural determinants rather than individual responsibilisation. Policy looked to civil society as well as business for solutions (Raffe, 2004) and since 1999, Scotland has been constructed as a 'happening place' (Mooney and Poole, 2004: 459) where social welfare is organised and discussed differently to rest of the UK. However, whilst 'Scottishness' became the frame there is no consensus as to what this means (Mooney and Williams, 2006): indeed, part of the 'Scottish myth' is that there exists a democratic, egalitarian system (Raffe, 2004). In general, though, it seems that support for public services is higher than in England and for some, Scotland stands as the last bastion of public service (Mooney and Scott, 2012).

Central to Scottish National Party (SNP) administrations since 2007 are three policy-making orientations (Sanderson, 2011). First, a shift to co-production, with local government, of policy, for example, The Children and Young People (Scotland) Act, 2014 (Scottish Government, 2014). Second, recognition of the potential for greater experimentation, for example through Getting it Right for Every Child (Scottish Government, 2018a). Third, the importance of evidence and analysis as in, for example, the National Improvement Framework (Scottish Government, 2018b). These contrast, partly, with previous central-surveillance techniques. The drive for Scottish renewal highlights and seeks to remedy structural elements under which inequality prospers. Drawing on the twin aims of demonstrating competence and moving towards independence, successive Scottish National Party administrations, since 2007, have sought to counterpoise economic prosperity with social justice. Between 1999 and 2007, and in somewhat contrast to the UK government's New Labour agenda setting, where policies were drawn from neoliberal tendencies, in Scotland the market played a much lesser role (Paterson, 2003b). Currently, while competitiveness is referenced 'outwards' towards others (the Nordic and Baltic States), creating a particular image of Scotland and displacing the historical 'other' of England (Arnott and Ozga, 2010a: 340), referencing is also 'inwards' to the ways in which Scotland might remain competitive. 'Modernised nationalism' mobilises 'nation' through inward calls to fairness and equality and outward calls to alignment with new comparators (Arnott and Ozga, 2010a: 347). Also, flourishing which emphasises community, fairness and inclusivity is promoted. Here education seeks wider agency: a shared idea of education as socially just is invoked: a referencing inwards to social democratic elements of the 'reshaping myths of Scottish education' (Arnott and Ozga, 2009: np) as a mechanism for the redistribution of resources.

However, since 2011, the Scottish policy landscape has had to deal with four issues (Mooney and Scott, 2012): a maturing of devolved government; changes in UK governance to a Rightist, Conservative position; the post-2008 economic crisis including Brexit; and, SNP majority/minority governments. In Scotland, political debate has shifted to the processes of achieving independence and a promotion of the kind of country an independent Scotland would be (Arnott and Ozga, 2009). Indeed, framing this against the economic crash of 2008 and Brexit has been the mainstay of the administration's approach; calls have concerned the deficiencies of devolved power in tackling economic and social matters (Arnott and Ozga, 2010b). Although independence was rejected in 2014, it was clear throughout the campaign that education was at the fore. More recently, in the Brexit 
debate, article 50 (the UK's formal notice to leave the EU), manifested in concerted efforts by the UK Government to seize control of both the process and product of leave (Arnott, 2017). Regional parliaments and assemblies have been side-lined and Scottish calls for differential arrangements with the EU post-Brexit have been rejected. These paint a particular picture for education and partnership working.

\section{Teacher education reform}

The time period discussed above has seen shifts in Scottish education as a result of wider social policy and politics. For the purposes of this chapter we wish to concentrate on the ways in which partnership working between universities, schools and local authorities has developed. Specifically, we focus on partnership in the development of the Donaldson Report in 2011 and how this has been taken forward, or not, in subsequent years. The conditions for the Donaldson Report, as seen above, were very much of change and renewal; specifically, teachers were seen as significant players in the educational process. Concerns about workload had, to some extent, been addressed in the McCrone agreement (Scottish Executive, 2000; 2001), and Curriculum for Excellence (Scottish Executive, 2006) required school staff to be agents of development.

The Donaldson Review subsequently called for renewed professionalism via theoretical knowledge (from universities) and practical knowledge (within schools and local authorities) through collaborative partnership. Although the act of commissioning the Donaldson Review might suggest that prior provision was deemed inadequate, there was, pointedly, a lack of clarity around what actually led to the Review's establishment (Menter \& Hulme, 2011; Smith, 2011). Despite this, the opening pages of the review try to make the case:

'Over the last 50 years, school education has become one of the most important policy areas for governments across the world. Human capital in the form of a highly educated population is now accepted as a key determinant of economic success. This has led countries to search for interventions which will lead to continuous improvement and to instigate major programmes of transformational change. Evidence of relative performance internationally has become a key driver of policy. That evidence suggests, perhaps unsurprisingly, that the foundations of successful education lie in the quality of teachers and their leadership. High quality people achieve high quality outcomes for children.' (Donaldson 2011: 2)

Kennedy and Doherty (2012: 836) suggest this is an explicit call for a 'globalised move to perform well internationally' through, for example, the Programme for International Student Assessment (PISA) and was in line with global meta-narratives that a highly educated population leads to strong, national, economic performance.

The Review was unusual in that it spanned the entire spectrum of teacher education from entry into Initial Teacher preparation and included: a commissioned literature review (Menter, Hulme, Elliot \& Lewin, 2010); a formal call for evidence (which received 99 submissions); a teacher survey (2381 responses); meetings with stakeholders; and, meetings with individuals and organisations across Scotland and internationally. While the review appeared to take a consultative approach, providing multiple opportunities for stakeholder engagement, little information was provided about the process by which obtained information was translated into recommendations. 
The review led to Teaching Scotland's Future: Report of a review of teacher education in Scotland (Donaldson, 2011) and contained fifty teacher education recommendations. Although some were considered radical, the report was received positively. Many recommendations hinged on the development of teacher professionalism and positioned partnership working between local authorities, schools and Higher Education Institutions as central to the development of 'high quality' teachers. However, it noted, on partnership, 'progress... has been limited and improvements have not always been sustained' (Donaldson, 2011: 47). Moreover, while teacher professionalism is a contested concept (Sachs, 2016) (competing ideas attempt to define it in very different ways) each view has its own implications for initial teacher preparation, professional learning and conceptualisations of teaching. Although teacher professionalism is at the heart of Report, there was no attempt to define this. Indeed, in their analysis, Kennedy and Doherty (2012: 840) found 28 references to professionalism, and note seven different terms used to describe it: 'extended professionalism'; 'enhanced professionalism'; 'reinvigoration of professionalism'; 'redefined professionalism'; 'wider concept of professionalism'; 'reconceptualised model of professionalism'; and, 'twenty-first century professionalism'. They suggest an almost implicit view that readers will have a shared understanding.

In the absence of a definition, it is worth considering the ways that 'teacher', and teaching as a 'profession', are located within the Report. To start, the report noted teaching as an intellectual occupation, highlighted its complexity and made it clear that initial teacher education should remain within the context of higher education. It viewed teachers as 'expert practitioners' who are themselves the engines of progress; they are 'reflective', 'accomplished' and 'enquiring' 'professionals', who should be 'key actors in shaping and leading educational change' (Donaldson, 2011: 4): '[e]xtended professionals [who] are agents of change, not passive or reluctant receivers of externally imposed prescription' (Donaldson, 2011: 18). It noted the importance of teacher agency within education reform and thus appeared to align with Sach's (2003; 2016: 419) models of democratic and activist teacher professionalism 'premised on a conscious form of social movement' with the ultimate aim of improving working conditions and the status of teaching. Importantly, though, the Report contained little information about how the system would support teachers to do this and given the centrality of agency to the overall vision of professionalism promoted, this is challenging.

The Report also required all teachers to see 'themselves as teacher educators and be trained in mentoring' (Donaldson, 2011: 73). Donaldson was clear: 'every teacher will be engaged in professional dialogue with peers' (ibid). This goes beyond only supporting early career teachers; it is a general statement about a new culture of professional learning whereby teachers informally (and formally) support one another. Although the Report acknowledges this requires improved 'mentoring and coaching skills', which should be 'developed and refreshed through initial teacher education, induction and CPD' (ibid), there was a lack of guidance in relation to who should take responsibility and resource this. The Report also argues that teachers should take responsibility for identifying their own professional learning needs and appropriate support. It signalled shifts away from one-off courses and conferences, referred to as 'mass force-feeding' and 'cascading of guidance' (10), towards local, collaborative, professional learning closely linked to school outcomes. Informal and teacher-led professional learning were promoted as 'powerful tools': 'self-evaluation', 'reflection', 'inquiry', 'peer observation' and 'teachers... learning from each other's practice' (p. 96) all featured. At one level, such 'in-house' measures could, it might be argued since 2008, be a feature of increasing calls for austerity. This is, we believe a churlish line to take; clearly the Donaldson Report desired to position new ways of collaborating professionally to further teacher learning. In line with the shift, possibly towards teaching as a 'Masters-level Profession', 'advanced study' and the addition of opportunities to gain Masters credits during ITE were highlighted as central to the Report's vision of 'enhanced 
professionalism'. While Masters-level study might fit with the idea of teacher-led, professional learning, it is different from informal, classroom-based teacher inquiry in that it typically occurs within Higher Education institutions and requires substantial funding. Finally, the Report recommended that the GTCS Professional Standards should be revised in order to align with the 'reconceptualised model of teacher professionalism' (68).

Within this frame of professionalism, a main plank of Donaldson was a call to develop and strengthen partnership between local authorities, schools and universities. With regard to Initial Teacher preparation it acknowledged the difficulties in striking a balance in such matters but that there '...is now a need to create a new kind of collaborative partnership within which all aspects of the student's development are a shared responsibility and respective roles and responsibilities are clear' (Donaldson, 2011: 7). The report recommended that new models for partnership be introduced based on jointly agreed principles and shared responsibility. The report was forthright: partnership is a valuable part of the ITE landscape and should be nurtured.

Following the report, all fifty recommendations were accepted (in full, in part or in principle) by the Scottish Government (Scottish Government 2011b), who then established a National Partnership Group to support delivery. This group, in operation from March 2011 to September 2012, discussed '...how the recommendations in Graham Donaldson's report... could be implemented' (Scottish Government, 2012: 2). It consisted of three sub-groups: Initial Teacher Education, Career-Long Professional Learning (CLPL) and Leadership; a Reference Group; and, a main group to which these reported. Such is the 'Scottish style' of policy-making (Cairney, Russell \& St Denny, 2016; Hulme \& Kennedy, 2016) whereby government traditionally relies on consultation with certain stakeholders: the traditional 'policy community' (Humes, 1988; McPherson \& Raab, 1984). Historically, this has tended to be small and close-knit, with many of its members knowing each other on a personal basis (Humes, 1997). While this approach might be somewhat consensual and developmental (Menter \& Hulme, 2008), concerns have been raised about its tendency towards conservatism and resistance to change (Beck, 2016; Menter \& Hulme, 2008). It can be difficult for new people and ideas to enter such a tight-knit network, particularly given historical and traditional rules for operation.

The development and operation of the National Partnership Group aligned closely with this approach: individuals from the 'policy community' were invited onto all subgroups. A range of stakeholders were represented, including the GTCS, Education Scotland, the Association of Directors of Education, the Scottish Teacher Education Committee (now known as the Scottish Council of Deans of Education), Universities Scotland and the Scottish Government. Teacher unions were not formally represented; instead, a sample of individual teachers were invited to represent the teaching profession. While it is not unusual for government to create such groups during various stages of policy development, the sheer size and scope of representation was notable. The National Partnership Group and its three subgroups had thirty-one members, while the Strategic Reference Group had twenty-one. Notable here is how partnership working was, or was not, evident in the National Partnership Group. This presents an interesting incentive to partnership discussions. What follows are findings from research conducted with members of the National Partnership Group (Beck, 2016). As we are concerned with how partnership ideas were translated into practice, it makes sense to look at working within this space. To start, the criteria for membership appeared to be heavily swayed by the need for wide stakeholder representation. There was an assumption that wide-spread representation would lead to partnership working; however, the development of partnership is more complex than this. One member noted: 
I think that the National Partnership Group inevitably was a compromise - both in terms of who was on, how we operated, and the report we came up with... There was a lot of trying to find the common ground; trying to find the consensual ground; trying to be nice to each other.

This highlights some conservatism and resistance to change. Evident here is the way in which a consensual approach ultimately meant that need was not always realised. Also prominent was the way in which partnership as a concept was sometimes challenged; it was not seen as worthless, rather there was a lack of agreement.

Partnership is a daft concept at one level. You can hide all sorts of relationships underneath it. It's an umbrella term which makes us all feel warm and comfortable.... It was too polite. We didn't have the tussles... there were discussions but we didn't really put things on the table that we might have done...

It seemed, then, that discussions about partnership occurred, but the 'Scottish approach' generated consensus when, perhaps, this hindered the development of genuine partnership working.

The development and strengthening of partnership between local authorities, schools and Higher Education Institutions was attempted by bringing together such representation. However, the organisations involved operated in different contexts, with different understandings and requirements. Problems emerged, in part, from self-protective behaviour in relation to funding concerns: 'change might mean that the funding moves and the funding is becoming so tight... It is selfprotection isn't it.' Given the UK austerity agenda being followed at the time, it was probably to be expected that finance would come to the fore. Also, many of Donaldson's partnership recommendations required a shift in approaches to professional learning. Hence, the majority of members were surprised by the decision not to include representatives of teacher associations. This restriction of teacher voice had clear implications for development and contradicted with Donaldson's vision of teachers as 'agents of change'.

As well as restricted representation, teacher representatives raised concerns about their involvement, which might suggest a lack of support to participate. Clearly the teachers who were selected were not part of the 'traditional policy community' and for some, this was their first experience of formal partnership groups. The omission of teacher associations was seemingly a missed opportunity and the ways in which teacher-members saw themselves and their role within this group did not speak of partnership but isolation.

\section{Partnership: Where are we now?}

While Donaldson conceived of partnership as pervading all phases of teacher-learning, it is clear that, for the most part, partnership is mainly concerned with matters pertaining to initial teacher education. To operationalise partnership, all institutions of higher education have agreements with local authorities to determine the ways in which the system will support student teachers and career long professional learning. In 2015, Education Scotland evaluated this first phase of local authority/higher education partnerships (Education Scotland, 2015). This evaluation found that while there was strong commitment to deepening existing relationships and further developing dialogue at a national level, there was also work to be done to ensure that all within the system were aware of, and understood, their respective roles within each partnership. It found that 
[o]verall, there is a continued need to further strengthen partnership practices to bring about greater consistency within and across partnerships in students' experiences during ITE and Masters level learning. (Education Scotland, 2015: 3)

In the 2016 evaluation of Teaching Scotland's Future (Black, Bowen, Murray, \& Zubairi, 2016), local authority employees felt that partnerships with Higher Education Institutions was a tangible benefit coming out of the Donaldson Report, along with improved partnerships with other local authorities. For Higher Education Institutions, the main benefits were in improvements in working with schools. Conversely, awareness of such partnerships was not high, which resulted in limited contact by teachers with members of the Initial Teacher Education community. Furthermore, it was felt that the main contributors to partnerships were often Higher Education Institutions, and the focus for partnership had not extended much past Initial Teacher Education and Leadership matters.

An examination of partnership, as part of the Measuring Quality in Initial Teacher Education (MQuITE) Project, funded, by Scottish Government, is currently being undertaken. This is a six-year project running from 2017 to 2022. As part of this, at the end of the 2017/2018 academic year, Higher Education tutors were surveyed for their views on ITE. From this, two partnership themes emerge: the need for co-operation and collaboration; and, holism and implications for the Standards for Provisional Registration (SPR). These echo the ways in which partnership both constructs and is constructed by the rights, duties and obligations brought to bear by all. Whilst Higher Education tutors signal a desire for more partnership, quite how this is to be actioned is not clear. Many of the Higher Education Institution tutors note teachers as 'caring', 'supportive', 'open' with a desire to see 'greater dialogue' between schools and universities '...outside of the specific context of the student they have before them.' Here, partnership working is seen as more than sharing observations of student teaching: Higher Education tutor/School staff working together to '...continue to develop positive relationships with partnership schools to share and discuss expectations.' The language Higher Education staff deploy extends the sphere of influence for both they and school staff into a common space for shared understanding and common action. Of concern seems to be the development of ways of working that transcend placement to support the development of all actors. In part this is aspirational, for it recognises the practical problems in partnership working (cf. Ong'ondo \& Jwan, 2009). While, in some instances, Higher Education staff position school staff as professionals unable (or unwilling) to take up partnership, here, they recognise that for some school staff, the rights, duties and obligations required by partnership are not always actionable for the ways in which schools are currently configured and the impact this has on the time and wherewithal of school staff to engage in partnership orients the teacher as 'victim': circumstances conspire to prevent them undertaking their role. While the position for the Higher Education Institution is as partner, their staff not only question the ability of some school staff to mentor, they also question whether some schools have the capacity to be able to undertake partnership working more broadly.

Additionally, much was made by Higher Education Institution staff about the assessment of student teachers and the role for National Standards for Registration (GTCS (General Teaching Council Scotland), 2012). At one level there was a belief that standards offer a clearly articulated means for student learning and that Higher Education staff are confident in their use. Such positions can be questioned, though, for the ways in which they construct the 'subject' (Ortlipp, 2009). Standards operate on a belief that beginning teaching can be subsumed to a set of statements that are easily assessable and which 'capture' learning teaching. In some ways, Higher Education staff position this as unproblematic, however, by noting that standards extend the right, duty and obligation to describe and affirm professional standing, these come to present a marketable mechanism for entry. In effect, 
what is created is a regime of truth: the standards come to represent objective fact about teaching (Ortlipp, 2009). Some Higher Education staff question this. First, they speak of how standards cannot form the sole basis for judgement; its end-point perspective is unfulfilling as a means to '...assess students' progress at any time prior to the end of their programme.' Rather, what is desired is '...a more inquiry-oriented standard which asks students to reflect on their decision-making.' Second, the 'view from everywhere' position offered by standardisation is challenged; such a position deploys expectation as both process and product. In the former, the student is a learner with attendant expectations of growth, development and achievement. In the latter, placement is positioned as attainment: proving practice rather than improving it.

Higher Education staff views on assessment speak of student learning as a 'whole-endeavour'. Some spoke of the need for standards as aspiration while others noted the equal importance of all standards. If assessment on placement was not already viewed as holistic, the aspiration was certainly so oriented. What seems evident is that higher education staff desire to work within an assessment regime which understands and operationalises wider conceptions of partnership than just the observation of student-teaching. For Higher Education tutors, partnership and the use of standards is problematic. On the one hand standards are seen as a mechanism for establishing expectations and making judgements. Conversely, there is a desire to blur the lines between the positions held by student, school tutor and Higher Education tutor, and the process and product of partnership and attendant decisions. What is notable is a desire for Higher Education staff to work in conjunction with school staff to ensure successful partnership. Although partnership policy (in the form of Donaldson) and theory suggests collaborative ways of working, it is clear that for higher education staff such methods are often lacking; accordingly, what ensues is often the segregation of school and university, bound only by the mechanistic ideas of standards.

\section{Conclusion}

All of the above paints a picture of desires to see partnership as a collaborative endeavour between all actors. As aspirational, though, there are tensions between the Donaldson Report and recent policy surrounding matters such as: the introduction of standardised assessment (through the National Improvement Framework (Scottish Government, 2018b)); proposed changes to school governance and the implications that both of these have for teacher education (Scottish Government, 2017); and, professional learning. While the Donaldson Report celebrated teacher agency along with wider social policy and political endeavours seemingly orienting Scottish education towards holistic matters, recent policy might indicate distinct shifts towards a system of teacher accountability and measurement. Further, a 2016 parliamentary debate on the content of Initial Teacher Education programmes across Scotland, and subsequent attempts to 'measure' hours dedicated to specific areas such as literacy and numeracy, suggests that new concerns are being raised about the quality of Initial Teacher Education (Scottish Government, 2017).

Initial Teacher Education has, though, never been immune to political wrangling, and it is no surprise that partnership has come in for scrutiny. This chapter paints a picture that notes, on the one hand, messages about the need to work together to improve the teacher-learning experience. On the other, it demonstrates that not all parts fit together. The language deployed may bear testament to partnership being taken seriously, however, the ways in which this is operationalised do not always match expectations. What we argue here, is that partnership is a national issue that needs a local approach. It is clear that professionalism was not initially conceptualised sufficiently well for national moves to take hold and how this feeds into partnership is vague and, at times, lacking in detail. There is good work (MQuITE demonstrates this), but as a systematic concept driving forward quality Initial 
Teacher Education and Career Long Professional Learning, partnership seems not to be fully realised. It is, then, a matter for local partnerships to determine the ways and means by which shared working can operate.

\section{References:}

Akkerman, S., \& Bruining, T. (2016). Multilevel Boundary Crossing in a Professional Development School Partnership. Journal of the Learning Sciences, 25(2), 240-284. https://doi.org/10.1080/10508406.2016.1147448

Allen, J. M. (2011). Stakeholders' perspectives of the nature and role of assessment during practicum. Teaching and Teacher Education, 27(4), 742-750. https://doi.org/10.1016/j.tate.2010.12.004

Allen, J. M., Ambrosetti, A., \& Turner, D. (2013). How school and university supervising staff perceive the pre-service teacher education practicum: A comparative study. Australian Journal of Teacher Education, 38(4), 108-128. https://doi.org/10.14221/ajte.2013v38n4.9

Allen, J. M., Howells, K., \& Radford, R. (2013). A "Partnership in Teaching Excellence": Ways in which one school-university partnership has fostered teacher development. Asia-Pacific Journal of Teacher Education, 41(1), 99-110. https://doi.org/10.1080/1359866X.2012.753988

Anderson, R. (2018). Historical Perspectives. In T.G.K. Bryce, W.M. Humes, D. Gillies \& A. Kennedy (Eds.), Scottish Education, $5^{\text {th }}$ Edition. Edinburgh University Press: Edinburgh.

Arnott, M. (2017) The SERA lecture 2016: "Jigsaw puzzle" of education policy? Nation, State and Globalised Policy Making, Scottish Educational Review, 49(2), 3-14.

Arnott, M. \& Ozga, J. (2009) Education Policy and the SNP Government, no.50, June 2009, available at http://citeseerx.ist.psu.edu/viewdoc/download?doi=10.1.1.469.39\&rep=rep1\&type=pdf

Arnott, M \& Ozga, J. (2010a) Education and nationalism: the discourse of education policy in Scotland, Discourse: Studies in the Cultural Politics of Education, 31(3), 335-350

Arnott, M. \& Ozga, J. (2010b) Nationalism, governance and policymaking in Scotland: The Scottish National Party (SNP) in power, Public Money and Management, 30(2), 91-96

Bartholomew, S. S., \& Sandholtz, J. H. (2009). Competing views of teaching in a school-university partnership. Teaching and Teacher Education, 25(1), 155-165. https://doi.org/10.1016/j.tate.2008.07.001

BBC (2012). EIS attacks SNP move to end chartered teacher scheme. Available at. Accessed 26th November 2019.

Beck (2016)

Black, C., Bowen, L., Murray, L., \& Zubairi, S. S. (2016). Evaluation of the Impact of the Implementation of Teaching Scotland's Future. Edinburgh.

Bowcott, O. \& Carrell, S. (2019). Scottish court ruling: what happens next in prorogation dispute? The Guardian, 11th September. Available at https://www.theguardian.com/politics/2019/sep/11/scottish-court-ruling-what-happensnext-in-prorogation-dispute

Cairney, P., Russell, S., \& St Denny, E. (2016). The 'Scottish approach' to policy and policymaking: what issues are territorial and what are universal? Policy \& Politics, 44(3), 333-350.

Cohen, E. (Sayag), Hoz, R., \& Kaplan, H. (2013). The practicum in preservice teacher education: A review of empirical studies. Teaching Education, 24(4), 345-380. https://doi.org/10.1080/10476210.2012.711815

Education Scotland. (2015). Aspect Review of the Education Authority and University ITE Partnership Arrangements (phase one). Livingston.

Furlong, J., Campbell, A., Howson, J., Lewis, S., \& McNamara, O. (2006). Partnership in English initial 
teacher education: changing times, changing definitions - evidence from the teacher training agency national partnership project. Scottish Educational Review, (37), 32-45.

GTCS (General Teaching Council Scotland). (2012). The Standards for Registration: mandatory requirements for Registration with the General Teaching Council for Scotland. Edinburgh: GTCS. https://doi.org/10.3837/tiis.2014.10.016

Humes, W. (1988). The leadership class. Edinburgh: Scottish Academic Press.

Humes, W. (1997). Analysing the policy process. Scottish Educational Review, 29, 20-29.

Kennedy, A., \& Doherty, R. (2012). Professionalism and partnership: panaceas for teacher education in Scotland? Journal of education policy, 27(6), 835-848.

LilleJord, S., \& Børte, K. (2016). Partnership in teacher education-a research mapping. European Journal of Teacher Education, 39(5), 550-563. https://doi.org/10.1080/02619768.2016.1252911

Maandag, D. W., Deinum, J. F., Hofman, A. W. H., \& Buitink, J. (2007). Teacher education in schools: An international comparison. European Journal of Teacher Education, 30(2), 151-173. https://doi.org/10.1080/02619760701275552

McPherson, A., \& Raab, D. (1984). Governing education: A sociology of policy since 1945. Edinburgh: Edinburgh University Press.

Menter, I. \& Hulme, M. (2008). Is small beautiful? Policy-making in teacher education in Scotland. Teachers and Teaching: theory and practice, 14(4), 319-330.

Menter, I., \& Hulme, M. (2011). Teacher education reform in Scotland: National and global influences. Journal of Education for Teaching, 37(4), 387-397.

Menter, I., Hulme, M., Elliot, D. \& Lewin, J. (2010). Literature review on teacher education in the $21^{\text {st }}$ century. Edinburgh: Scottish Government.

Mooney, G. \& Scott, G. (2012) Devolution, social justice and social policy: the Scottish context. In G. Mooney and G. Scott (Eds.) Social Justice and Social Policy in Scotland, Bristol: The Policy Press

Mooney, G. \& Williams, C. (2006) Forging new 'ways of life'? Social policy and nation building in devolved Scotland and Wales, Critical Social Policy, 26(3), 608-629

Munn, P., Stead, J., McLeod, G., Brown, J., Cowie, M., McCluskey, G., \& Scott, J. (2004). Schools for the 21st century: the national debate on education in Scotland. Research Papers in Education, 19(4), 433-452.

Paterson, L. (2003b) 'The three educational ideologies of the British Labour Party, 1997-2001', Oxford Review of Education, 29(2), 165-186

Raffe, D. (2004) How distinctive is Scottish education? Five perspectives in distinctiveness, Scottish Affairs, 49, 50-72

Rauschenberger, E., Adams, P., \& Kennedy, A. (2017). Measuring Quality in Initial Teacher Education A Literature Review for Scotland's MQulTE Study, 1-87. Retrieved from http://www.scde.ac.uk/wp-content/uploads/2017/10/MQulTE-Lit-Review-FINAL-Oct-2017.pdf

Sachs, J. (2003). The activist teaching profession. Buckingham: Open University Press.

Sachs, J. (2016). Teacher professionalism: Why are we still talking about it?.Teachers and Teaching, 22(4), 413-425.

Sanderson, I. (2011) Evidence-based policy or policy-based evidence? Reflections on Scottish experience, Evidence and Policy, 7(1), 59-76

Scott, G. \& Wright, S. (2012) Devolution, social democratic visions and political reality in Scotland, Critical Social Policy, 32(3), 440-453

Scottish Executive. (2000). A Teaching Profession for the $21^{\text {st }}$ Century: The report of the Committee of Inquiry into professional conditions of service for teachers. Scottish Executive: Edinburgh.

Scottish Executive. (2001). A Teaching Profession for the $21^{\text {st }}$ Century: Agreement reached following recommendations made in the McCrone Report. Scottish Executive: Edinburgh. 
Scottish Executive. (2006). A Curriculum for Excellence: Progress and proposals. Scottish Executive: Edinburgh.

Scottish Government. (2012). Teaching Scotland's Future - National Partnership Group: Report to Cabinet Secretary for Education and Lifelong Learning. Scottish Government: Edinburgh.

Scottish Government. (2014) Children and Young People (Scotland) Act 2014. Available at https://www.legislation.gov.uk/asp/2014/8/contents/enacted.

Scottish Government (2017). Initial teacher education: content analysis 2017. Available at https://www.gov.scot/publications/initial-teacher-education-content-analysis-2017/.

Scottish Government. (2018a) Getting it right for every child (GIRFEC). Available at https://www.gov.scot/policies/girfec/.

Scottish Government. (2018b) 2019 National Improvement Framework and Improvement Plan. Available at https://www.gov.scot/publications/2019-national-improvement-frameworkimprovement-plan/.

Smith, I. (2011). Re-visiting the Donaldson Review of Teacher Education: Is creative innovation secured. Scottish Educational Review, 43(2), 17-38.

Smith, I., Brisard, E., \& Menter, I. (2006). Models of partnership developments in initial teacher education in the four components of the United Kingdom: Recent trends and current challenges. Journal of Education for Teaching, 32(2), 147-164. 